\title{
WESITE PENYEDIAN INFORMASI RUMAH KOS KAB.INHIL Studi Kasus: Sebagian Rumah Kos Yang Ada Di Tembilahan
}

\section{BayuRianto}

\author{
ProgramStudiSistem Informasi,UniversitasIslamIndragiri \\ Jln.ProvinsiParit1Tembilahan-IndragiriHilir-Riau \\ Email:rianto.bayu91@gmail.com
}

\begin{abstract}
In connection with the development of information technology, naturally it will force the public to utilize the technology to the maximum extent possible from all aspects of life. Of course information varies, one of which is for students and students who will go to college or study in a place far from where they live. For this reason, it is clear at this time that students and students must immediately find a temporary residence to be used as their residence until the study is complete.

The need for proper education has increased rapidly or significantly. Being aware of this, the author, builds a website-based boarding house information system, as a means of providing effective housing information for boarders, tenants, and managers Kons house to promote boarding houses that will be rented and manage everything related to boarding houses on the website quickly, easily, and up to date. Boarding house is a flat or single house that was built with the aim of being rented with a period of less than a month or annually or more. Website development uses the waterfall method, whereas for modeling using UML (unifield modeling language). The modeling languages used are PHP and XAMPP for databases. Website Keb.Inhil Boarding House Information Provision is complemented by booking rented houses online to facilitate prospective boarding-dwellers without having to go straight to the field to order a boarding house.
\end{abstract}

Keywords: Technology, Website, Database, Boarding House

\begin{abstract}
Abstrak
Sehubungan dengan semakin berkembangnya teknologi informasi, maka dengan sewajarnya akan memaksa masyarakat dalam memanfaatkan teknologi tersebut dengan semak simalmungkin dari segala segi kehidupan. Informasi tentunya bermacam-macam, salah satunya adalah untuk para mahasiswa dan siswa/siswi yang akan menjalani kuliah ataupun bersekolah ditempat yang jauh dari tempat tinggal. Untuk itu jelas pada saat tersebut membuat mahasiswa dan siswa/siswi tersebut harus segera mencari tempat tinggal sementara untuk dijadikan tempat tinggal meraka sampai studi selesai.

Kebutuhan akan pendidikan yang layak telah mengalami peningkatan yang sengat pesat atau segnifikan.. Menyadari akan hal tersebut maka Penulis, ,membagun sebuah system informasi rumah kos berbasis website, sebagai sarana penyediaan informasi tempat tinggal yang efektif bagi para pencari kos ,penyewa,maupun bagi pengelola rumah kons untuk mempromosikan rumah kos yang akan di sewakannya dan mengelola segala hal yang berkaitan dengan kos tersebuat di website secara cepat, mudah, dan terkini. Rumah kosadalah rumah susuan atau rumah tunggal yang dibangun dengan tujuan di sewakan dengan jangaka waktu sebulan ataupun pertahun maupun lebih. Pembangunan website menggunakan metode waterfall, sedangkan untuk pemodelan mengunakan UML ( unifield modeling language). Bahasa pemodelan yang digunakan adalah PHP dan $X A M P P$ untuk database. Website Penyediaan Informasi Rumah Kos Keb.Inhil ini di lengkapi dengan pemesana rumah kontrakan secara online untuk memudahkan calon penghuni kos tanpa harus langsung turun lapangan untuk memesan rumah kos.
\end{abstract}

Katakunci:Teknologi, Website, Database,Rumah Kos 


\section{Pendahuluan}

\subsection{Latar Belakang}

Sehubungan dengan semakin berkem bangnya teknologi informasi, maka dengan sewajarnya akan memaksa masyarakat dalam memanfaatkan teknologi tersebut dengan semaksimal mungkin dari segala segi kehidupan. Informasitentunya bermacammacam, salah satunya adalah untuk para mahasiswa dan siswa/siswi yang akan menjalani kuliah atau pun bersekolah ditempat yang jauh dari tempat tinggal. Untuk itu jelas pada saat tersebut membuat mahasiswa dan siswa/siswi tersebut harus segera mencari tempat tinggal sementara untuk dijadikan tempat tinggal meraka sampai studi selesai.

Rumahkos- kosan adalah tempat tinggal sementara yang disewa bagi orang yang merantau atau orang yang rumahnya jauh dari tempat tujuan rutinitas sehari-hari khususnya mahasiswa dan siswa/siswi yang mencariilmu yang jauh dari tempat tinggal mereka, Seiring 1.2 RumusanMasalah

Dari

uraiandiatasdapatdirumuskanpermasalahan yang di timbulkansebagaiberikut :

1. Sulitnyaparapencarikostmengatahuihargako st yang sesuaidengankeadaan, sehinggapencarikostbisa

menyesuikandengan buget ataudana yangada.

2. Pencarikostsulitmengetahuilokasidanpasilit as yang sesuaidengankehendakatau yang dinggikan.

3. Dan padaumumnyapromosi dari pemilik kost dilakukan dengan memasang pelang yang

bertulisanterimakostputraatauputrijadimasi hkuranginovatif.

4. Dan yang terjadipadasaatinimasyarakatmelakukansur veylangsung yang jelasmemakanwaktu, tenaga yang cukupbanyakuntukhanyasekedarsurvey.

\subsection{Tujuan Penelitian}

bertambahnya penduduk di kotaTembilahan, sering kali orang-orang yang mencaritempatkost mengalamikendala. Kendala yang banyakdialamiantara lain jumlah peminat yang banyak tidak sebanding dengan jumlah tempat kositusendiri. Selain itu pencari tempat kos adalah mayoritas orang-orang yang baru pindah atau pendatang dari berbagai daerah kekota Tembilahan yang belum mengenal wilayah di kota Tembilahan dengan baik sehingga informasi yang lengkap mengenai tempat kos sanagt dibutuhkan bagi mereka yang mencari rumah kos atau kontrak. Latar belakang tersebut yang memberikan ide atau inspirasi penulis membuat solusi untuk mempermudah para teman-teman mahasiswa dan siswa/siswi utnuk lebih mudah mencari tempat tinggal sementara, atau dengan kata lain Tempat Kos / Kontrak. Untuk itu penulis mengambil judul"Website

\section{PenyediaanInformasiRumahKosKab.Inhil”.}

Tujuan Dari penelitian website penyediaa ninformasi rumah kost Kab.Inhil dapa tdirumuskan sebagaiberikut :

1. Untukmemudahkanparapencarikostuntukm enemukankost yang sesuaiharga, danpasilitasyang di ingikan.

2. Untukmemudahkanparapemilikkost mempromosikan

3. ataumengimformasikankost yang dimilikinya.

4. Membantupencarikost menemukankosanberdasarkan informasi yang diberikanolehsistem.

\section{MetodologiPenelitia}

\subsection{Definisi Sistem}

menyatakan bahwa sistem didefinisikan sebagai sekumpulan prosedur yang saling berkaitan dan saling terhubung untuk melakukan suatu tugas bersama - sama.[1]

\subsection{Definisi Informasi}

Informasi merupakan hasil pengolahan data 
sehingga menjadi bentuk yang penting bagi penerimanya dan mempunyai kegunaan sebagai dasar dalam pengambilan keputusan yang dapat dirasakan akibatnya secara langsung saat itu juga atau secara tidak langsung pada saat mendatang.[2] 2.3 Definisi Sistem Informasi

Sistem Informasi (SI) adalah kombinasi dari teknologi informasi dan aktivitas orang yang menggunakan teknologi itu untuk mendukung 2.5 Pengertian SDLC

SDLC atau software development life cycle atau sering disebut juga system development life cycle adalah proses mengembangankan atau mengubah suatu sistem lunak dengan menggunakan model - model dan metodologi yang digunakan orang untuk mengembangkan sistem - sistem perangkat lunak sebelumnya (berdasarkan best practice atau cara - cara yang sudah teruji baik). Seperti halnya proses metamorfosis pada kupu kupu, untuk menjadi kupu - kupu yang indah maka dibutuhkan beberapa tahap untuk dilalui, sama halnya dengan membuat perangkat lunak, memiliki daur tahapan yang dilalui agar menghasilkan perangkat lunak yang berkualitas.[5]

2.6 Pengertian Website

Banyak orang yang beranggapan website sama dengan internet. Padahal, website dan internet adalah hal yang berbeda. Website atau biasa disebut web, dapat diartikan sekumpulan halaman yang terdiri atas beberapa laman yang berisi informasi dalam bentuk data digital, baik berupa teks, gambar, vidio, audio, dan animasi lainya yang disediakan melalui jalur koneksi internet.[6]

\subsection{Xampp}

Xampp merupakan singkatan dari $\mathrm{x}$ ( empat sistem operasi apapun ). Apache, Mysql, PHP, dan Perl. Xampp adalah tool yang menyediakan paket perangkat lunak dalam satu buah paket.Dalam perangkat Xampp sudah terdapat apache ( web server ), Mysql ( database ), PHP ( server side scripting ), perl, FTP server, phpmyadmin, dan berbagai pustaka bantu lainya. Dengan menginstal Xampp, maka anda tidak perlu lagi melakukan instalasi dan melakukan konfigurasi web server apache, PHP, dan Mysql secara manual. Xampp akan otomatis menginstalasi dan mengonfigurasikan untuk anda.[7]

2.8 Mysql

Pada perkembangannya, Mysql disebut juga SQ1 yang merupakan singkatan dari structured query languange. SQ1 merupakan bahasa operasi dan manajemen. Dalam arti yang sangat luas, istilah sistem informasi yang sering digunakan merujuk kepada interaksi antara orang, proses algoritmik, data, dan teknologi.[3]

2.4 Pengertian Pengembangan Sistem

Pengembangan sistem dapat berarti menyusun suatu sistem yang baru untuk menggantikan sistem yang lama secara keseluruhan atau memperbaiki sistem yang telah ada.[4]

terstruktur yang khusus digunakan untuk mengolah database.[6]

2.9 PHP

PHP singkatan dari hypertext preprocessor yang merupakan server side programming, yaitu bahasa pemrograman yang diproses di sisi server.Fungsi utama PHP dalam membagun website adalah untuk melakukan pengolahan data pada database. Data website akan dimasukan ke database, diedit, dihapus, dan ditampilkan pada website yang diatur oleh PHP.[6]

\subsection{Website}

Website terdiri dari kumpulan file-file yang saling terkait dan tersimpan dalam satu foldar. Website merupakan lokasi yang akan digunakan untuk mengumpulkan file-file halaman web. Filefile dokomen web tersebut terdiri dari gambar, script css, audio dan sebagainya. Dengan banyak file-file yang membentuk suatu website, perlu dilakukan pengolahan file yang baik.[8] 


\section{Hasil dan Pembahasan}

\subsection{Pengertian Rumah kost}

Kost atau indekost adalah sebuah jasa yang menawarkan sebuah kamar atau tempat untuk ditinggali dengan sejumlah pembayaran tertentu untuk setiap periode tertentu ( umumnya pembayaran perbulan) kata "kost" sebenarnya adalah turunan dari bahasa belanada "in de kost". definisi "in de kost" sebenarnya adalah "makan didalam" bila dijabarkan lebih lanjut dapat pula berarti "tinggal dan ikut makan" di dalam rumah tempat menumpang tinggal.

\subsection{Analisa Sistem}

Sebelum dilakukannya perancangan sebuah sistem yang baru, diperlukan adanya suatu gambaran yang memuat keterangan atau informasi yang berhubungan dengan sistem yang ada sekarang atau sistem yang sedang berjalan pada organisasi yang bersangkutan.Hal ini bertujuan agar mempermudah dalam menganalisa dan merancang sistem yang baru.

Pada tahap analisis sistem dilakukan pengumpulan data dan menganalisa segala dokumen-dokumen yang digunakan pada sistem yang sedang berjalan. Ini dilakukan untuk memudahkan mengevaluasi kekurangankekurangan apa saja yang ada pada sistem tersebut yang selanjutnya merancang perbaikan-perbaikan pada sistem tersebut dan menyusun sistem baru. Selain itu juga dibahas analisis kebutuhan non-

Utuk mengetahui informasi atau berita menganai rumah kost masyarakat hanya bisa meliahat papan pengumuman atau secara langsung menayakan kepada pemilik rumah kost tersebut. Cara seperti ini kurang optimal, memerlukan waktu yang lama dan biaya yang lumayan banayak untuk melakukan observasi langsung.

\subsection{Perancangan Sistem Sistem Yang Baru \\ Rancangan sistem berguna untuk} memberikan gambaran kepada User tentang sistem yang diterapkan, guna mempermudah pemakaian dan memberi pemahaman atau pengertian tentang sistem website informasi rumah kost.

\subsubsection{Perancangan Sistem Secara Umum}

Perancangan Sistem pada Penelitian ini menggunakan metode Unified Modelling Language (UML) yang terdiri dari Use Case Diagram, Activity Diagram, Squence Diagram dan Class Diagram.

\section{Use Case Diagram}

Berikut ini gambar 3.2 adalah Use Case Diagram Sistem Informasi Kost : fungsional yang terdiri dari analisis perangkat keras, analisis perangkat lunak dan analisis user.

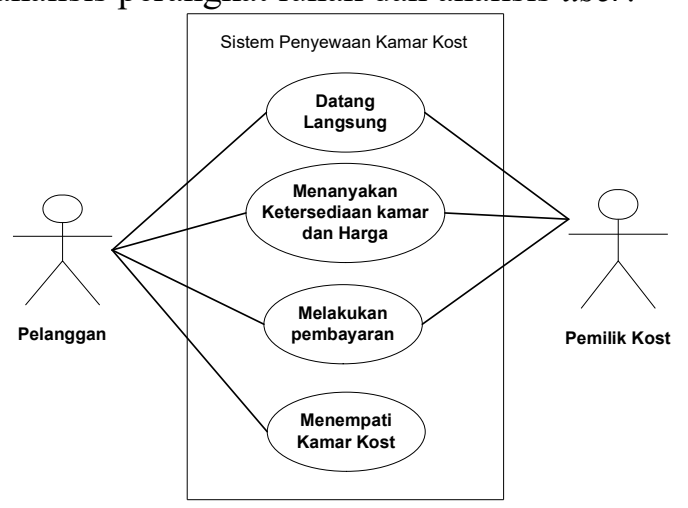

\section{Gambar 3.1 Sistem Yang Berjalan}

Pada gambar 3.1 menjelaskan dimana user melihat informasi rumah kost melalu papan pengumuman atau papan iklan dan untuk mendapatkan informasi yang lengkap mengenai kost dengan cara datang langsung ke pemilik kost.

\subsubsection{Analisa Sistem Yang Sedang Berjalan}

Berdasarkan dari hasil observasi dan wawancara yang telah dilakukan di berberapa kost yang ada di kabupaten Inhil. Penyampain informasi rumah kost hanya dengan papan pengumuman yang diletakan di depan rumah kost. Karena dalam pengolahan data informasi rumah kost masih secara manual, hal ini membuat penyampaian atau promasi rumah kost belum berjalan secara optimal karena terbatasan informasi tentang rumah kost.

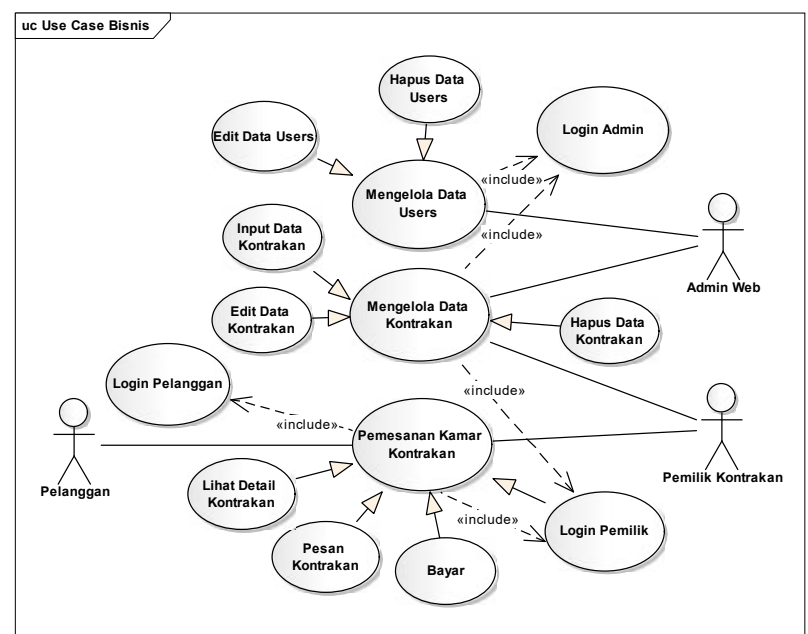

\section{Gambar 3.2 Usecase Diagram}

Pada use case diagram diatas, menggambarkan tentang bagaimana proses atau langkah-langkah dalam proses yang dilakukan seorang admin sebagai pengelola sistem mempunyai beberapa hak diantaranya mengakses data serta mengelola yang berhubungan dengan data kost dan data user, kemudian terdapat juga pemilik kost yang dapat mengelola data kost 
miliknya dan juga melakukan konfirmasi pemesanan, dan terakhir adalah pelanggan yang dapat memesan kost melalui website dengan menggunakan akun yang dimilikinya.

3.4 Rancangan Interface

Pada tahap perancangan interface ini akan digambarkan mengenai perancangan input dan

\subsubsection{Desain Input}

Berikut ini adalah rancangan menu input yang terdapat pada halaman website sistem informasi penyediaan informasi kamar kost :

1. Menu Login Pelanggan

Beranda Daftar Kost Cara Pembayaran Tentang Kami Login

\begin{tabular}{|l|}
\hline \begin{tabular}{l} 
Kostinhil \\
Informasi Rumah Kost \\
\hline Login Pelanggan \\
\hline \begin{tabular}{l} 
Email \\
Passord \\
\hline Login \\
\hline Register \\
\hline
\end{tabular} \\
\hline
\end{tabular}
\end{tabular}

Gambar 3.17 Rancangan Interface Login Pelanggan

Gambar 3.17 menggambarkan tentang menu login pelanggan yang terdapat pada halaman website, pelanggan perlu melakukan login untuk melakukan pemesanan kamar kost.

2. Input Data Pemesanan Pelanggan

Berikut ini adalah rancangan interface menu output program sistem informasi penyediaan informasi kamar kost :

1. Halaman Menu Utama

\begin{tabular}{|l|}
\hline Beranda Daftar Kost Cara Pembayaran Tentang Kami Login \\
\hline Ko S tinhil \\
Informasi Rumah Kost \\
\hline Daftar Rumah Kost \\
\hline
\end{tabular}

VI. IMPLEMENTASI

4.1 Halaman Login Admin perancangan output dimana keduanya sangat terkait dengan program aplikasi yang akan dibuat, input merupakan awal dari proses pengolahan data sedangkan output merupakan hasil dari proses pengolahan data.

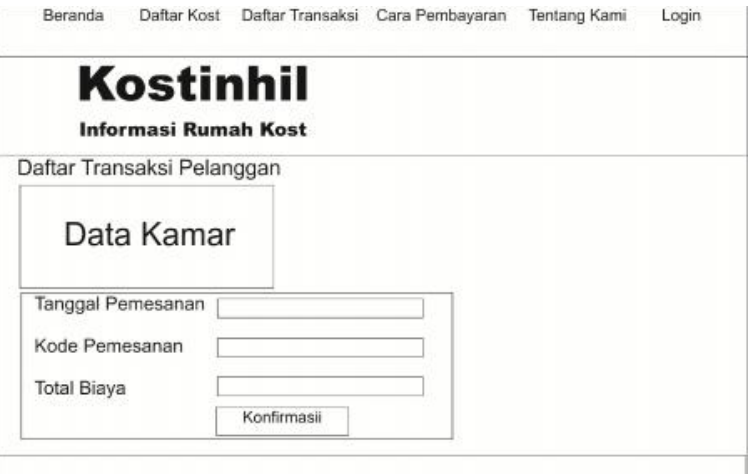

Gambar 3.18 Rancangan Interface Pemesanan Kamar Kost

Gambar 3.18 menggambarkan bagaimana form input untuk melakukan pemesanan kamar kost yang dilakukan oleh pelanggan. Adapun inputan yang perlu dilakukan adalah tanggal pemesanan, kode pemesanan, dan total biaya yang harus dibayar.

3.4.2 Menu Output

\section{Gambar 3.20 Rancangan Interface Halaman Menu Utama}

Pada gambar 3.20 diatas menjelaskan yakni menu utama yang terdapat pada website siste informasi penyediaan kamar kost, didalam menu utama akan tampil menu-menu yang terdapat pada website kemudian juga terdapat faftar rumah kost yang tersedia. 


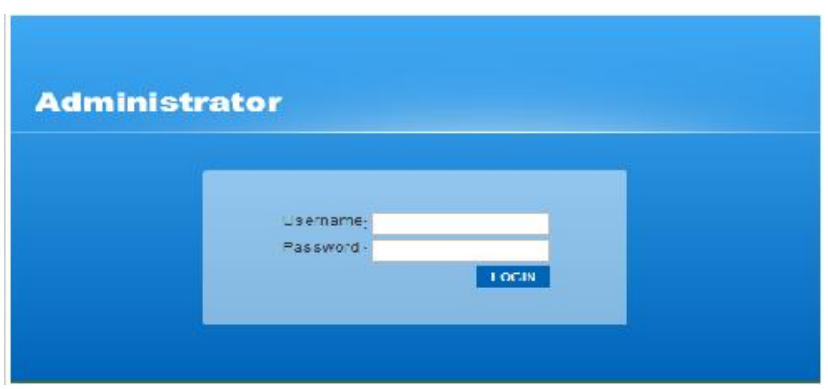

Gambar 4.1 Halaman Login Admin

adalah halaman Login administrator, untuk dapat melakukan login seorang admin harus memasukkan username dan password yang valid. 4.2 Input Data Pesanan Kamar

Berikut ini gambar 4.4 adalah form pemesanan kamar kost :

Pesan Kamar

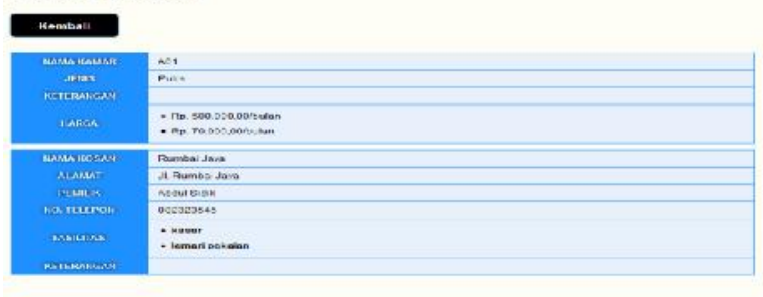

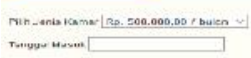

\section{Gambar 4.4 Input Data Pemesanan Kamar}

\section{KESIMPULAN}

Babinimerupakan babyangterakhir dari penulisanskripsiini, berisikankesimpulandan perbaikan-perbaikanyang yangmanapadababini saran-saranuntuk dianggapperluuntuk sistemyang adapada saat ini.Daripenjelasandan pembahasan padabab-bab sebelumnya, maka penulismencoba mengambil beberapa kesimpulan dansaran-sarandariuraiantersebut.

\subsection{Kesimpulan}

Dengan adanya pembuatan Website penyediaan informasi rumah kost ini, maka dapat disimpulkan perubahan-perubahan yang terjadi dalam pencarian rumah kost dan penyampaikan informasi terhadap masyarakat :

1. Dengan adanya Website penyediaan informasi rumah kost Ini masyarakat dapat dengan mudah mendapatkan informasi mengenai rumah koas yang ada di kawasan tembilahan.

2. Dengan adanya Website penyediaan informasi rumah kost Ini dapat memudah masyarakat dalam mencari rumah kos tampa harus mensurvey kelapangan di kernakan di dalam Dengan adanya Website penyediaan informasi rumah kost Ini sudah tercantum lokasi, kontak pemilik kos dan fasilitas yang di miliki kost tersebut.
Gambar 4.4 adalah form untuk melakukan input data pemesanan kamar kost, seorang pelanggan harus memilih jenis tarif sewa kamar yang tersedia kemudian melakukan input tanggal menempati kamar kost tersebut.

\subsection{Menu Utama}

Berikut ini gambar 4.6 adalah menu utama website Sistem Informasi pemesanan kamar kost :

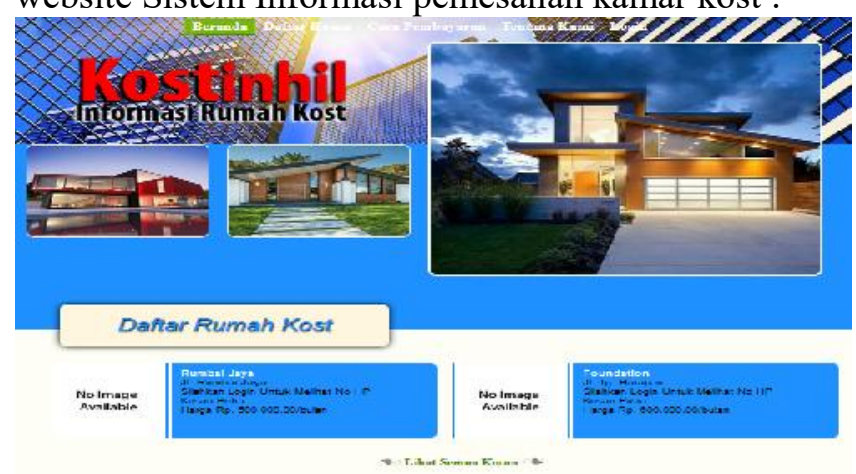

\section{Gambar 4.6 Menu Utama}

Menu Utama berisikan berita utama pada website Sistem Informasi pemesanan kamar kost, terdiri dari menu-menut yang tersedia pada website dan daftar kamar kost yang ada. 
3. Dengan diterapkannya Website penyediaan informasi rumah kost ini dapat mempromosikan rumah koast yang ada di tembilahan diranah publik sehingga lebih dikenal oleh Masyarakat Luas.

\subsection{Saran}

Berdasarkan hasil analisa yang telah dilakukan di bab-bab sebelumnya ada masukan yang dapat dikemukakan untuk pemgembangan Website penyediaan informasi rumah kost Keb.Inhil khususnya terhadap kebutuhan sistem dengan fungsional perangkat lunak, saran-saran tersebut adalah:

1. Sistem ini bukanlah sistem yang sempurna, artinya masih banyak kekurangan dan kelemahan, oleh karena itu dapat dilakukan pengembangan terhadap Website informasi

rumah kost ini agar fungsi-fungsinya lebih lengkap sesuai dengan kebutuhan.

2. Untuk Admin dan Pemilik rumh kost Website informasi rumah kost diharapkan untuk menjaga privasi username dan passwordnya, karena dikhawatirkan website disalah gunakan oleh pihak-pihak yang tidak berkpentingan dan tidak bertanggung jawab.

\section{DAFTAR PUSTAKA}

[1] I. A. E. Pratama, Sistem Informasi dan Implementasinya. Bandung: Informatika, 2014.

[2] D. E. Hendrianto, "Pembuatan Sistem Informasi Perpustakaan Berbasis Website Pada Sekolah Menegah Pertama Negeri 1 Donorojo Kabupaten Pacitan," vol. 3, no. 4, pp. 57-64, 2014.

[3] D. Rosadi and F. O. Andriawan, "Aplikasi sistem informasi pencarian tempat kos di kota bandung berbasis android," vol. 10, no. 1, pp. 50-58, 2016.

[4] T. Sutabri, Analisa Sistem Informasi. Yogyakarta: andi, 2012.

[5] M. S. A.S, Rossa, Rekayasa Perangkat Lunak. Bandung: Informatika, 2015.

[6] R. Abdulloh, Easy \& Simpel Web Programming. Tegal, Jawa Tengah, 2016.

[7] W. Komputer, Sistem Informasi Penjualan Online Untuk Tugas Akhir. andi, 2014.

[8] W. Komputer, Adobe Dreamwever cs5. Yogyakarta: andi, 2011. 